JOURNAL OF APPLIED CRYSTALLOGRAPHY

ISSN 1600-5767

\section{Scientific Leadership. By J. W. (Hans) Niemantsverdriet and Jan-Karel Felderhof. De Gruyter, 2017. Pp. xv+171. Price (paperback) EUR 29.95, USD 34.99, GBP 24.99. ISBN 978-3-11-046888-5.}

\author{
John R. Helliwell*
}

Keywords: book reviews; scientific leadership.

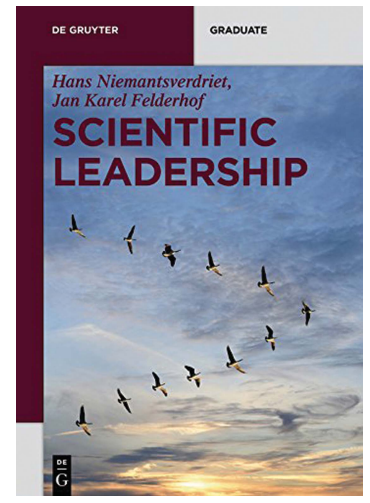

(C) 2018 International Union of Crystallography
School of Chemistry, The University of Manchester, Brunswick Street, Manchester M13 9PL, UK. *Correspondence e-mail: john.helliwell@manchester.ac.uk

This book, Scientific Leadership, I gladly accepted to review. I had included the topic in §VI of my book Skills for a Scientific Life (Helliwell, 2016) and so I am obviously interested in it. In her review of my book, Elena Boldyreva (2017) drew my attention to the book by Hans Selye (1977), a scientific leader of the time in physiological aspects of stress, which I immediately purchased. A book by Kathy Barker (2010) focuses solely on leading one's laboratory. I had devised my Skills book to include aspects of the scientific method and various roles I had played, but it is also a manual comprising many chapters, each being a 'how to' description which readers can dip into as needed. I included the harnessing of the tools of managerialism but also considered its ills, at least as seen in universities by myself and often described in the Times Higher Educational Supplement.

This book by Niemantsvverdriet and Felderhof focuses on scientific leadership and is geared towards a person becoming a leader and to following managerialist techniques. As I read the contents pages I wondered about the last chapter's How to implement selfleadership and the 3B-6T-9E enhancement philosophy in your organization. So I began...

The contents of the book are as follows:

Foreword; Acknowledgments; Special foreword; Contents; 1 . Creating success in your own scientific world; 2. Leading yourself and others in research; 3. Presenting science: talks, publications, posters, and some ideas on conferences; 4 . Management skills for researchers; 5. Planning the road to your future in science: strategy and comprehensive plans; 6 . Understanding how to build successful teams: creating synergy between people who trust each other; 7. On the road to scientific (self) leadership; 8. Post scriptum-implementation; Worksheets; Index.

The front cover is labelled 'GRADUATE'. The back cover states the book's aims: 'Modern Science is teamwork. But how can young academics go from being a productive member of a scientific team to leading their own? Entry level positions for PhDs in Science often require the infamous 'people skills'. The authors aim to equip young academics with the right ideas and strategies for their scientific leadership development. Become a successful leader not with tricks, but with an inspiring and straightforward vision and mission, the correct mindset, and effective teamwork.'

On page 9 I learnt why the book cover image was chosen: ' ... people have to understand the goals and needs of their organization thoroughly, and they need to dispose over sufficient freedom to operate and decide. Terms like 'self-steering', 'self-management', and even authentic 'self-leadership' have entered the scene; hierarchical structures tend to become less dominant. In its ultimate form, third-generation governance and control rely on unique abilities and strong points of individuals, who together operate like a flock (see cover illustration). The situation determines which abilities are needed most, and as in an effective flock of geese, the leadership changes according in an almost automatic fashion.' I was unsure at this point what the message was. Personally I think it important to assess any theories of what scientific leadership is with some very well known examples. For such I always start with Albert Einstein. We can immediately see that his huge leadership 
example does not fit a 'flock of geese' model. However, as Abraham Pais's superb biography of Einstein shows (Pais, 1982), Einstein did refrain from citing others when he really should have done, notably Lorentz and Poincare in his 1905 special relativity paper. So he might be deemed in a flock of three geese, to be fair.

From the book's section on presentations a reader will get some clear and very good advice, such as page 60 - 'The best advice on making effective slides is probably to remove all information that is not strictly necessary.' - although I am unsure why they qualify it with 'probably'. We are also shown an excellent example of the wrong and right way to present a rather complicated set of curves so that a reader can 'immediately concentrate on the meaning of the data'. There are some oddities in the authors' coverage, however. They seem to assume a standard length of a talk being 20-30 min. They also advocate the use of intermediate conclusions being mentioned at the end of each section of a talk. They do not mention the main hazard of this, which is the audience assuming an earlier finish than the speaker has planned. At the IUCr Hyderabad Congress in the commercial exhibition I saw on the Springer recent and new books display that there was a whole book on scientific presentations (Alley, 2013). I bought a copy and read it cover to cover. I was impressed with Alley's advice and immediately set about adding some further polish to one of my recent presentations, which had already gone very well. This illustrates the depth and breadth to which one can go on these topics.

Chapter 4 of Niemantsvverdriet and Felderhof's book covers a variety of management skills for researchers. This I found to be generally good and sound. But again there were odd things about it. Firstly, the tool of risk estimation and mitigation seems to me obligatory and incredibly useful but was not covered. Secondly, the example on page 86 involved a project to be managed on a Dean's instructions for developing a teaching course in computer skills for first year students, i.e. not a research project example at all. Thirdly, the traffic lights system of managing projects, namely red to stop a project, amber to pause it and green to continue it, is simple but effective, I find. This, too, is not discussed. Fourthly, for a scientific leader to aspire to executing a project so well that its Gantt chart might be 'a nice wall chart in your laboratory to show visitors' I found rather strange. If what we are about is science and discovery, then much hoped for is the unexpected finding, be it graphene or a pulsar to name two of the most well known unexpected discoveries, which of course will be outside a Gantt chart's planning and scope.

The strengths of the authors in approaching people and situations with managerial tools comes to the fore with the final section of chapter 4, 'Conflict management'. This section concerns conflicts between team members in a laboratory and the strategies that can be adopted to move on. The authors link the different ways of dealing with such conflicts with their earlier chapter 2 (e.g. Fig. 2.1) on the 'four operational personality dimensions' and types of personalities. They also have a very nice section on Relationship management, namely the developing of good contacts and retaining them.
A further example of harnessing good tools that stem from a managerialist approach is their advice on the systematization of consulting one's students, colleagues or coworkers ('the team'). This includes brainstorming together and use of green, yellow and red coloured paper notes for identifying success, issues needing attention or failure, respectively, in one's organization. This can then also be mapped onto a diagram of Vision, Strategy and Outside relations as shown in their vivid Fig. 5.7 on page 106 . On page 110 we learn the meaning of the '3B Principle': 'be oneself, belong to the group and be valued'. This notion is expanded on in $\$ 6.4$ entitled The $3 B$ approach to authentic resources. The authors see them as 'essential prerequisites for establishing trust, mutual respect, an open culture for critical and constructive exchange of ideas, and pride in achieving shared goals'. I feel that the language leaves scope for confusion here and find it difficult to know what the authors really intend. That said the authors do bring out in a sparkling way one of their other tools, the understanding of different personality types in a research group, which allows one to see what happens, or might happen, in teams with differing examples of mixtures of personality types (pages 115-117). On page 125 we learn the meaning of 3B-6T-9E, and I quote: 'Forgive us for dubbing our approach to (self) leadership as the 3B-6T-9E concept.

$3 B$ (be oneself, belong to the group and be valued) the three requirements for authentic behaviour

$6 T$ as the six stages in the trajectory to realizing a grand plan (Triggers, Talents, Thrives, Thrills, Trails and Track)

$9 E$ as the nine elements for developing skills and building up experience (including skills for autonomous and team performance and devising strategies for creating high impact).'

This is too much jargon, I think.

On page 134, Fig. 7.4, we learn the core of why they value the team versus the individual. But the approaches of both an individual and a team are needed, I think, and great things can be achieved by both. So, in all this managerialism, I felt, there is too little acknowledgement of what science is, be it the variety of scientific methods (Helliwell, 2016) or the very philosophical aspects such as articulated by Chalmers (1999) or Selye (1977). But common sense and good analysis come to the fore on page 143 with the authors' analysis of encouraging and discouraging workplace environments.

A major strength of the book is its guest columns. Advice from successful leaders is invaluable, and the authors have chosen well from ones they know personally; on pages 14-15 Jens Rsitruo-Nielsen, a former research director in industry and a founding member of the European Research Council, writes about the concept that Research should be managed by motivation not by control; on pages 71-72 Prof Graham Hutchings, Professor of Physical Chemistry and Director of the Cardiff Catalysis Institute at Cardiff University, writes on Time, money and great ideas; and on page 124 Yong-Wang Li presents a motivational vision on how Science is the right guide for a safe and sustainable future for our world.

I have highlighted aspects above, the good and the questionable, in an evidence-based way. What do I think is missing from the book? A gap in coverage is what to do (i.e. practical 


\section{book reviews}

advice) about bad leadership. The authors may quite reasonably say such leaders should read their book and improve themselves! There also could be some comment and guidance for scientific leaders on achieving a proper gender balance. This book would benefit from having a much bigger ethical dimension, I think. Overall would I recommend this book? Actually I would because its intent is very sincere, although the language and style I identify with managerialism, which I also rebel against, creative spirit that I am. But that said I can see good tools from managerialism that can be of help in realizing one's scientific dreams, ideas and hunches (my terminology).

\section{References}

Alley, M. (2013). The Craft of Scientific Presentations. Critical Steps to Succeed and Critical Errors to Avoid. New York: Springer Science and Business Media.

Barker, K. (2010) At the Helm. Leading your Laboratory. New York: Cold Spring Harbour Press.

Boldyreva, E. V. (2017). J. Appl. Cryst. 50, 1241-1242.

Chalmers, A. F. (1999). What is This Thing Called Science?, 3rd ed. Guildford, Kings Lynn: Biddles.

Helliwell, J. R. (2016). Skills for a Scientific Life. Boca Raton: CRC Press. Pais, A. (1982). Subtle is the Lord: The Science and Life of Albert Einstein. Oxford University Press.

Selye, H. (1977). From Dream to Discovery. On Being a Scientist. New York: Arno Press. 